\title{
Beyond a feeding and thermoregulatory structure: toucan's bill as a sword and pincer
}

\author{
André de Camargo Guaraldo ${ }^{1,2,3}$, Letícia Mara Ceolin Antqueves ${ }^{1} \&$ Lilian Tonelli Manica $^{1}$ \\ Laboratório de Ecologia Comportamental e Ornitologia, Universidade Federal do Paraná, Curitiba, PR, Brazil. \\ Universidade Federal de Juiz de Fora, Juiz de Fora, MG, Brazil. \\ 3 Corresponding author: guaraldoac@gmail.com
}

Received on 22 August 2018. Accepted on 05 August 2019.

\begin{abstract}
Toucans (Ramphastidae) have always attracted researcher's attention for their exuberant bill shape and size, which function has been often related to feeding strategies and thermal regulation. In this study, we discuss the importance and use of the bill by Ramphastidae species in intraspecific disputes. We present novel data and video recordings on agonistic encounters between females of the Spot-billed Toucan Selenidera maculirostris, along with a compilation of data from the Brazilian citizen science platform WikiAves and previous studies on six other Ramphastidae species. Until now, only a couple of species was known for using their bill in fights against conspecifics. Our study highlights the between-species behavioral similarities and the widespread occurrence of such behavior in the family, suggesting that this may be more common than previously thought and proposing hypotheses on the likely roles of such intraspecific contests.
\end{abstract}

KEY-WORDS: agonistic behavior, citizen science, female disputes, Ramphastidae, Selenidera maculirostris.

\section{INTRODUCTION}

Since the observations of bill morphology variations in Darwin's finches and their relationships with feeding habits (Grant 1981), there has been a noteworthy interest for the relationships of this structure with birds' ecology and behavior (e.g., Podos 2001). Besides its main use for feeding, some bird species also use their bill as warfare tool against predators (e.g., mobbing) and in agonistic conspecific disputes for resource, territory and mate (e.g., Murphy et al. 2009, Rico-Guevara \& Araya-Salas 2014). Despite intraspecific agonistic encounters also occur irrespective of individuals sex, literature is often biased towards male-male interactions (Clutton-Brock 2007). Nevertheless, studies show that in some species such as monkeys (Koenig et al. 2004) and anhingas (Sazima \& D'Angelo 2012) females may fight for resources or even for dominance over each other (e.g., crickets; Delago \& Aonuma 2006).

Females were historically perceived as passive, little aggressive, or coy (Darwin 1871), but modern less biased approaches have been revealing how improper this is (e.g., Hrdy 2006). Besides the currently accepted assertion of females' role on sexual selection of male traits and ornaments (Andersson 1994, Andersson \& Simmons 2006), females may also play key-roles in territory establishment and competition for mates (Clutton-Brock 2007 \& 2009, Rosvall 2011). In this study we provide a jointly interpretation of the bills' function and the female role in ecological behavior, adding to the perspective of bills use as weapons by disputing females.

\section{METHODS}

The Neotropical toucans (Aves: Ramphastidae) have one of the most noteworthy bill morphology, which is not only tightly related to feeding behavior (Bühler 1995) - assisted by a strong leg musculature (Moermond \& Denslow 1985) - and thermoregulation (Tattersall et al. 2009, Hughes 2014), but also seems to be a dueling weapon (Van Tyne 1929, Brydon 1995, Ehrlich et al. 2001, Ritterson \& Stein 2011). During regular fieldwork days in July 2008, at an Atlantic Forest reserve, in southeast Brazil - Ilha do Cardoso State Park, Cananeia, São Paulo state -, we recorded two events of a novel agonistic dispute between females of the Spot-billed Toucanet Selenidera maculirostris. In the next lines, we describe these encounters in detail (video recordings available as supporting material (Suppl. 1), followed by the results of a comprehensive review for similar agonistic behavior in other Ramphastidae species. Then, and to the best of our knowledge, we conclude with the first ever discussion on the recurrence of this behavior and its likely functions in the family. 


\section{RESULTS \& DISCUSSION}

We registered - with binoculars $(10 \times 42)$ and camera (Sony DSC-H1) from about $15-25 \mathrm{~m}$ distance - the first agonistic encounter at a point where a trail crosses a lowland pristine forest area (approximate coordinate: $\left.25^{\circ} 04^{\prime} 46^{\prime \prime} \mathrm{S} ; 47^{\circ} 55^{\prime} 36^{\prime \prime W}\right)$. At $\sim 07: 30$ h (GMT -3) on 10 July 2008, we spotted and heard two females flapping and ruffling wings atop $(-12 \mathrm{~m})$ of a tree. Females (hereafter referred to as A and B) were repeatedly beating and pecking each other using their bill in an apparent attempt to dislodge each other from the perch. When females were spotted, female A was biting the right-side facial skin and feathers of female B. Both females were vigorously flapping their wings and shaking their body with their legs. Some seconds after this "bill wrestling" started, female A managed to push B so the later got hanging down the perch being solely suspended by A's bite. After $-40 \mathrm{~s}$ flapping its wings, B got rid of female A's bill, quickly reverting the situation: female $B$ managed to bite A's face and push it hanging down the perch. Then, female A's feet slipped off the perch one at a time and she stood belly up while holding female B's head. After $-12 \mathrm{~s}$ in that position, female B's feet loosened from the perch and both individuals fell for $-5 \mathrm{~m}$ high. During the fall, female A remained still and holding B's head which opened the tail feathers and flapped wings four times in an apparent attempt to control the fall. When both hit some leaves and branches, they got loose and flew to opposite directions. During all the fight, a male remained quiet and still on a nearby tree $(-15 \mathrm{~m})$, apparently watching the fight, and flew to a perch near female B where both stayed for a few minutes until fly out of sight.

The second event occurred on 13 July, about 1.5 $\mathrm{km}$ far from the first $\left(25^{\circ} 5^{\prime} 33^{\prime \prime} \mathrm{S} ; 47^{\circ} 55^{\prime} 35^{\prime \prime} \mathrm{W}\right)$ in the under-canopy of a primary forest area and again involved two females (C and D). Despite all birds had no natural or artificial markings and observations occurred far from each other, it is uncertain these were independent behavior, i.e. performed by distinct pairs of females. At 08:05 h, we heard one female $(\mathrm{C})$ perching on a tree at $-10 \mathrm{~m}$ high, apparently at the end of a pursuit flight after another female (D), which perched on a nearby branch. After a few seconds, female D went to the same branch C was and both started "bill wrestling" as did females A and B. In the beginning, both kept striking each other's bill, but at times females kept pulling each other while their bills were interlocked: while one was biting the other's lower mandible, the latter was biting the former's upper mandible. Females remained around $2 \mathrm{~min}$ in this dispute, when female C finally bit D's left-side facial feathers near to its throat. With that, female C pushed D until she got hanging down the perch. After $-12 \mathrm{~s}$, female D slipped off the perch, but differently from the dispute between females A and B, female D could not hold herself on $\mathrm{C}$, which kept flapping its wings at times and moved along the perch while twisting and shaking the hanging opponent. After $-13 \mathrm{~s}$, female D beat its wings and managed to grab C's throat with its left foot, which in turn reduced the amplitude of the shaking movements. Females remained in this position for $-45 \mathrm{~s}$, when D's feet got loose and she got being suspended again by C. Approximately 13 s latter, D slipped off C's bill (a single clap sound could be heard) and free fell about $2 \mathrm{~m}$ until she flew to a nearby lower perch $-4 \mathrm{~m}$ away. After a couple of minutes, D flew back to the wrestling perch and restarted bill strikes and interlocking for another 3-4 min. Then, a male, which remained still and quiet on a nearby perch $(-10 \mathrm{~m})$ during the entire duration of the fight, flew and perched aside female $\mathrm{C}$ and on the opposite side of female D. At this point, females where facing each other, perched on different branches, and kept fighting with no noticeable behavioral change upon male's arrival. A few seconds after that, and despite leaves obstructed the observers' sight, female C seemed to have bitten D's, forcing its head down (noticed through its raising tail). After $-10 \mathrm{~s}$, another bill clap could be heard, at the same time that female D flew away. Female $\mathrm{C}$ kept wiping its bill for a few times and then flew to a nearby upper perch. The male remained in the perch for another 1-2 min and then followed female C. This entire fight lasted $\sim 11 \mathrm{~min}$, vs. -2 min in the first event, but we caution that these are incomplete data since we only spotted both fights when they were already ongoing. We heard no vocalization of the females or of any other individual during any of the events.

We run an extensive literature review for evidences of aggressive behavior in other Ramphastidae species. In Google Scholar (www.scholar.google.com), we ran searches combining the family name with all the following terms (one at a time), both in English and Portuguese: female, agonistic behavior, agonistic encounter, aggression, dueling, and fight. This resulted in only one reference explicitly describing aggressive behaviors in Ramphastidae (e.g., fence duelling in Ramphastos sulphuratus brevicarinatus; Van Tyne 1929) and one record of Pteroglossus aracari killing each other in captivity in two events with no further details (Pernalete 1989). Further unstructured literature review led us to three other references, two for P. torquatus erythropigius (Brydon 1995) and one for $R$. ambiguus swainsonii (Ehrlich et al. 2001, Ritterson \& Stein 2011). In addition to the literature review, we also searched for evidences in two large citizen science databases, the Internet Bird Collection (www.hbw.com/ibc) and WikiAves (www. wikiaves.com.br). We narrowed the research to all species occurring in Brazil, for which there was more available data $(27,707$ records at the WikiAves as of 19 April 2016 
and 1023 at the IBC), totaling 22 species (Piacentini et al. 2015), about $60 \%$ of all 34 extant Ramphastidae (RemsenJr. et al. 2017). We analyzed each and all existing photos and videos for every species in those databases. With that, we successfully found a few additional evidences that four other species may have similar aggressive behavior: the Toco Toucan Ramphastos toco (record made in August at Cataguases, southeast Brazil; Filho 2012) the Channelbilled Toucan $R$. vitellinus (in September at Macapá, north Brazil; Albano 2012), the Red-breasted Toucan $R$. dicolorus (in October at Campos do Jordão, southeast Brazil; Rodrigues 2012), and the Chestnut-eared Aracari Pteroglossus castanotis (in June at Foz do Iguaçu, south Brazil; Bolivar 2012).

All three Ramphastos species showed agonistic behaviors very similar to those described above for the Spotbilled Toucanet. However, it was impossible to assign the sex of individuals involved in those records because sexes are identical or have inconspicuous dimorphism. Thus, insofar our report for the Spot-billed Toucanet aggression is the first in describing exclusively female-female fencing contests in Ramphastidae. In all cases involving Ramphastos species, one individual used its bill to hold the other suspended bellow the perch. Observer's notes for the $R$. vitellinus record describe that both individuals slipped off the perch, likely free falling while flapping its wings. In this case, there is no report of the presence of a third individual. For the other two Ramphastos species, the individual that remained perched held the other suspended by its throat, but what happened in $R$. dicolorus record after that remains uncertain. From this point on, we describe the disputes involving $R$. vitellinus and $P$. castanotis, extracting as many details as possible from the observers reports (Albano 2012, Bolivar 2012). Prior to the moment when one individual of $R$. vitellinus was held hanging by the other, both birds struck each other with their bills (Albano 2012). When individual A pushed and held B suspended by its throat, a third bird perched aside A and attacked B for $-90 \mathrm{~s}$ (Albano 2012). After that, B fell motionless to the forest floor, but it remains uncertain if the individual died (Albano 2012). In the P. castanotis record, two birds got their bills interlocked, with one of them being held suspended. The observer describes that all other four or five individuals in the flock were apparently trying to break the birds apart by hanging themselves on the suspended individual and striking both birds bills (Bolivar 2012). After $-4 \mathrm{~min}$, the two birds were set apart, fell to the ground for a few seconds and all flew away (Bolivar 2012).

This is the first time that any intraspecific agonistic behavior is formally described for these five ramphastid species ( $R$. toco, $R$. vitellinus, $R$. dicolorus, $S$. maculirostris and $P$. castanotis). Moreover, the resemblance of such behavior among species is noteworthy. In fact, the confrontations reported for two species of the family $-R$. ambiguus swainsonii (Ehrlich et al. 2001) and P. torquatus erythropygius (Brydon 1995, Ritterson \& Stein 2011) are very similar, the latter culminating in death of one individual. In all cases, authors suggested intraspecific within-group dominance hierarchy as the motif for the fights, perhaps associated with male-male disputes for females. Thus, our study is the first to confirm that females could also act in such within-sex disputes. Altogether, this behavior is currently recorded for $-23 \%$ of all Ramphastidae species ( $n=9 R$. toco, $R$. a. swainsonii, $R$. s. brevicarinatus, $R$. vitellinus, $R$. dicolorus, $S$. maculirostris, $P$. t. erythropygius, $P$. aracari, and $P$. castanotis) and is widespread through all family clades (Hughes 2014). Therefore, it is plausible that this behavior also occurs in other species of the family, representing an additional role of the bill morphology and a likely result of morphological and behavioral coevolution, which deserves further study. Ramphastidae have well developed leg muscles, which importance was so far related to their feeding strategy of reaching and picking fruits hanging upside down and at the tip of branches (Moermond \& Denslow 1985). Our observations add to these findings, since such anatomical adaptation seems also to be an important individual trait in fights. Individuals with stronger legs should have higher success rates in disputes, as it would be more able to hold still while pushing and holding its opponent hanging below the perch. We also suggest additional and more comprehensive anatomical evaluations not only of leg, but also of jaw muscles (e.g., Bühler 1995), in an attempt to reveal further morphological specializations and their ecological and behavioral roles.

The context of all aggressive contests described in this study allows inferences on the adaptive value of this behavior within the family. In species which individuals often live alone (e.g., R. toco), flocks (e.g., R. vitellinus), or in (socially) monogamous pairs such as $S$. maculirostris (Sick 1997), such behavior may represent a dispute for matting and/or territory. Since only females of the latter species were actively observed fighting while males remained as spectators, we propose three non-excluding hypotheses that the aggression may be (i) a female's strategy to compete for food resources or even for nesting cavities (e.g., Christianini 2018), (ii) to reduce male extra-pair copulation, likely ensuring the highest male parental care to the offspring, and (iii) a consequence of sex ratio bias towards males in this species, leading to a more intense and frequent female dispute for a mate (Rosvall 2011). The aggression in $S$. maculirostris occurred a month prior to its known nesting period at Ilha do Cardoso (Guaraldo \& Staggemeier 2009), which could indicate a role as pre-breeding dispute for mating and nesting territory establishment. This behavior may be more widespread among Ramphastidae species than previously 
documented, since all but one record (July, dry period in Costa Rica; Brydon 1995) occurred during each species' breeding period. An exception to a breeding-context disputes is $P$. castanotis, in which the role of fights is less clear and could range from contests for mating to withingroup hierarchical position establishment. We believe that future studies of marked individuals are mandatory for allowing researchers to test these hypotheses.

\section{ACKNOWLEDGEMENTS}

Authors thank to the editor and reviewer who ensured improvements to the manuscript, to the managers of PE Ilha do Cardoso for allowing access to the area and to Israel Schneiberg for comments on a previous version of the manuscript. A.C.G. thanks CAPES for post-doctoral fellowship (PNPD \#1459754).

\section{REFERENCES}

Albano C. 2012. WA745941, Ramphastos vitellinus Lichtenstein, 1823. http://www.wikiaves.com/745941 (Access on 08 March 2017).

Andersson M. \& Simmons L.W. 2006. Sexual selection and mate choice. Trends in Ecology \& Evolution 21: 296-302.

Andersson M.B. 1994. Sexual selection. Princeton: Princeton University Press.

Bolivar T. 2012. WA676101, Pteroglossus castanotis Gould, 1834. http://www.wikiaves.com/676101 (Access on 18 April 2017).

Brydon A. 1995. Intraspecific aggression in Pale-mandibled Aracari Pteroglossus erythropygius. Cotinga 3: 55.

Bühler P. 1995. Größe, form und färbung des tukanschnabels: grundlage für den evolutiven erfolg der Ramphastiden? Journal für Ornithologie 136: 187-193.

Christianini A.V. 2018. Several cavity-nesting birds fight for a single tree hollow in an Atlantic Forest fragment: consequence of increasing nest-site limitation? Revista Brasileira de Ornitologia 26: $12-14$.

Clutton-Brock T. 2007. Sexual selection in males and females. Science 318: 1882-1885.

Clutton-Brock T. 2009. Sexual selection in females. Animal Behaviour 77: 3-11.

Darwin C. 1871. The descent of man, and selection in relation to sex. London: Murray.

Delago A. \& Aonuma H. 2006. Experience-based agonistic behavior in female crickets, Gryllus bimaculatus. Zoological Science 23: 775-783.

Ehrlich P.R., Bailey S.-A., Bush E., Davis T. \& Girshick S. 2001. Dominance behaviour in toucans. Cotinga 16: 64-66.

Filho J.O. 2012. WA720270, Ramphastos toco Statius Muller, 1776. http://www.wikiaves.com/720270 (Access on 09 March 2017).

Grant P.R. 1981. Speciation and the adaptive radiation of Darwin's finches: the complex diversity of Darwin's finches may provide a key to the mystery of how intraspecific variation is transformed into interspecific variation. American Scientist 69: 653-663.

Guaraldo A.C. \& Staggemeier V.G. 2009. Breeding of the Spot-billed Toucanet (Selenidera maculirostris) in the wild. Wilson Journal of Ornithology 121: 807-809.

Hrdy S.B. 2006. Empathy, polyandry, and the myth of the coy female, p. 131-159. In: E. Sober (eds.). Conceptual issues in evolutionary biology. Cambridge: Bradford Books.

Hughes A.L. 2014. Evolution of bill size in relation to body size in toucans and hornbills (Aves: Piciformes and Bucerotiformes). Zoologia 31: 256-263.

Koenig A., Larney E., Lu A. \& Borries C. 2004. Agonistic behavior and dominance relationships in female Phayre's Leaf Monkeys preliminary results. American Journal of Primatology 64: 351-357.

Moermond T.C. \& Denslow J.S. 1985. Neotropical avian frugivores: patterns of behavior, morphology, and nutrition, with consequences for fruit selection. Ornithological Monographs 36: 865-897.

Murphy T.G., Rosenthal M.F., Montgomerie R. \& Tarvin K.A. 2009. Female American Goldfinches use carotenoid-based bill coloration to signal status. Behavioral Ecology 20: 1348-1355.

Pernalete J.M. 1989. Breeding the Black-necked Aracari Pteroglossus aracari at Barquisimeto Zoo. International Zoo Yearbook 28: 244246.

Piacentini V.Q., Aleixo A., Agne C.E., Maurício G.N., Pacheco J.F., Bravo G.A., Brito G.R.R., Naka L.N., Olmos F. \& Posso S. 2015. Annotated checklist of the birds of Brazil by the Brazilian Ornithological Records Committee. Revista Brasileira de Ornitologia 23: 91-298.

Podos J. 2001. Correlated evolution of morphology and vocal signal structure in Darwin's finches. Nature 409: 185-188.

Remsen-Jr. J.V., Cadena C.D., Jaramillo A., Nores M., Pacheco J.F., Robbins M.B., Schulenberg T.S., Stiles F.G., Stotz D.F. \& Zimmer K.J. 2017. A classification of the bird species of South America. http://www.museum.lsu.edu/ Remsen/SACCBaseline. htm (Access on 22 April 2017).

Rico-Guevara A. \& Araya-Salas M. 2014. Bills as daggers? A test for sexually dimorphic weapons in a lekking hummingbird. Behavioral Ecology 26: 21-29.

Ritterson J.D. \& Stein A.C. 2011. Deadly intra-specific aggression in Collared Aracari Pteroglossus torquatus. Cotinga 33: 80.

Rodrigues C.T. 2012. WA1513327, Ramphastos dicolorus Linnaeus, 1766. http://www.wikiaves.com/1513327 (Access on 18 April 2017).

Rosvall K.A. 2011. Intrasexual competition in females: evidence for sexual selection? Behavioral Ecology 22: 1131-1140.

Sazima I. \& D'Angelo G.B. 2012. Agonistic interactions between two foraging Anhinga females in southeastern Brazil. Wilson Journal of Ornithology 124: 403-405.

Sick H. 1997. Ornitologia brasileira. Rio de Janeiro: Nova Fronteira.

Tattersall G.J., Andrade D.V. \& Abe A.S. 2009. Heat exchange from the toucan bill reveals a controllable vascular thermal radiator. Science 325: 468-470.

Van Tyne J. 1929. The life history of the toucan Ramphastos brevicarinatus. Michigan: University of Michigan.

Associate Editor: Cristiano S. Azevedo. 